\title{
The flushing of pollution from recreational boating in tidal embayments with application to Great Salt Pond on Block Island
}

\author{
S. Mecca ${ }^{1}$, W. Brown ${ }^{1} \&$ R. Barber ${ }^{2}$ \\ ${ }^{1}$ Department of Engineering-Physics-Systems, Providence College, \\ Providence, RI 02918, USA \\ ${ }^{2}$ Computational Science and Engineering Department, \\ STFC Daresbury Laboratory, Warrington, WA4 4AD, UK
}

\begin{abstract}
Pollution loading from recreational boating has been gleaned from seasonal boat count data, published results of pollutant releases from marine engines, and boat type and size distributions from marine association data. These loading functions have then been used in the single-basin MSB model of pollution-flushing, a systems-dynamic model written in Stella (Stella is a product of ISEE Systems, Inc., formerly High Performance Systems of Hanover, New Hampshire, USA), which has been validated in tank tests and in a specific application to Great Salt Pond on Block Island. The results of the present study allow the concentration of various aqueous pollutants associated with the propulsion component of recreational boating to be computed in well-mixed tidal embayments.
\end{abstract}

Keywords: tidal prism, pollution flushing, tidal embayment, recreational boating pollution, Great Salt Pond Block Island.

\section{Introduction}

While coastal embayments are likely to benefit from 'no discharge' regulations, recreational boating adds a number of pollutants from marine engine use to basins that serve as harbors for these vessels. The MSB single-embayment model [1] offers a graphical and numerical representation of the process of pollution flushing from well-mixed tidal embayments. The model, which is written in Stella (Stella is a product of ISEE Systems, Inc., formerly High Performance 
Systems of Hanover, New Hampshire, USA), allows for realistic basin bathymetries, cascading basins [2] as well as the dynamic loading of pollutants [3]. The governing rate equations driving the model are the same as those found in the analytical tidal prism model developed by Barber [4] for constant pollution loading and simple basin geometries. The governing equations are derived from the following mass flow equation:

$$
\frac{d(C V)}{d t}=V \frac{d C}{d t}+C \frac{d V}{d t}=Q C+k
$$

where $Q$ is the discharge through the mouth of the embayment and $k$ is the pollution loading rate, which may be time-dependent. During the ebb flow period, $d V / d t=Q$, allowing the $Q C$ term on the right-hand side of eqn. (1) to be cancelled with the $C d V / d t$ term on the left. During the flood flow period, the $Q C$ term on the right-hand side of the equation can be assumed to be zero, provided the pollution return-flow rate into the basin is ignored. This results in two rate equations for $d C / d t$, one for the ebb and another for the flood conditions.

One of the crucial parameters in the MSB model is the pollution return-flow factor, $b$. This parameter is used to modify the volume of the tidal prism to account for the return of polluted water during the flood tide. This methodology has been discussed by Barber [4] and more theoretically by Sanford et al. [5]. The volume-modifying factor is taken as $(1-b)$, where $b$ varies between 0 , for no return flow, and 1, for total return flow. The MSB model [1] employs the basic state variable approach used in systems dynamics to represent the governing mass flow rate equations, treating the time-varying pollutant concentration, $C$, in the embayment as a level. The model has been validated against analytical and experimental data [4] and more recently has been applied to Great Salt Pond on Block Island, where in 1986 a Rhodamine dye study was conducted [6,7]. The results provide the first real basin validation of the MSB model.

The present paper extends the MSB model to study the flushing of pollutants associated with marine engines involved in recreational boating and applies the model to Great Salt Pond on Block Island where boat counts were graciously provided by the Harbourmaster and the Harbour Office. Pollutant data was gleaned from a number of studies [8-16] and coupled with boat type- and lengthdistributions, the model was expanded to define an appropriate loading factor, $k$, for the pollutant under consideration. An interface was written to allow for these factors to be changed for different embayments and boating data. Results for a typical season are presented for Great Salt Pond.

\section{Great Salt Pond and boating data}

Great Salt Pond is situated on Block Island, which is part of the State of Rhode Island and situated in the Atlantic Ocean at the entrance to Long Island Sound at a latitude of $41.191^{\circ} \mathrm{N}$ and a longitude of $71.575^{\circ} \mathrm{W}$. The population of Block Island is little more than 1000 but this swells to 10,000 or more during the summer. Much of this increase is related to boating activities around Great Salt Pond, the bathymetry of which is shown in Figure 1. 


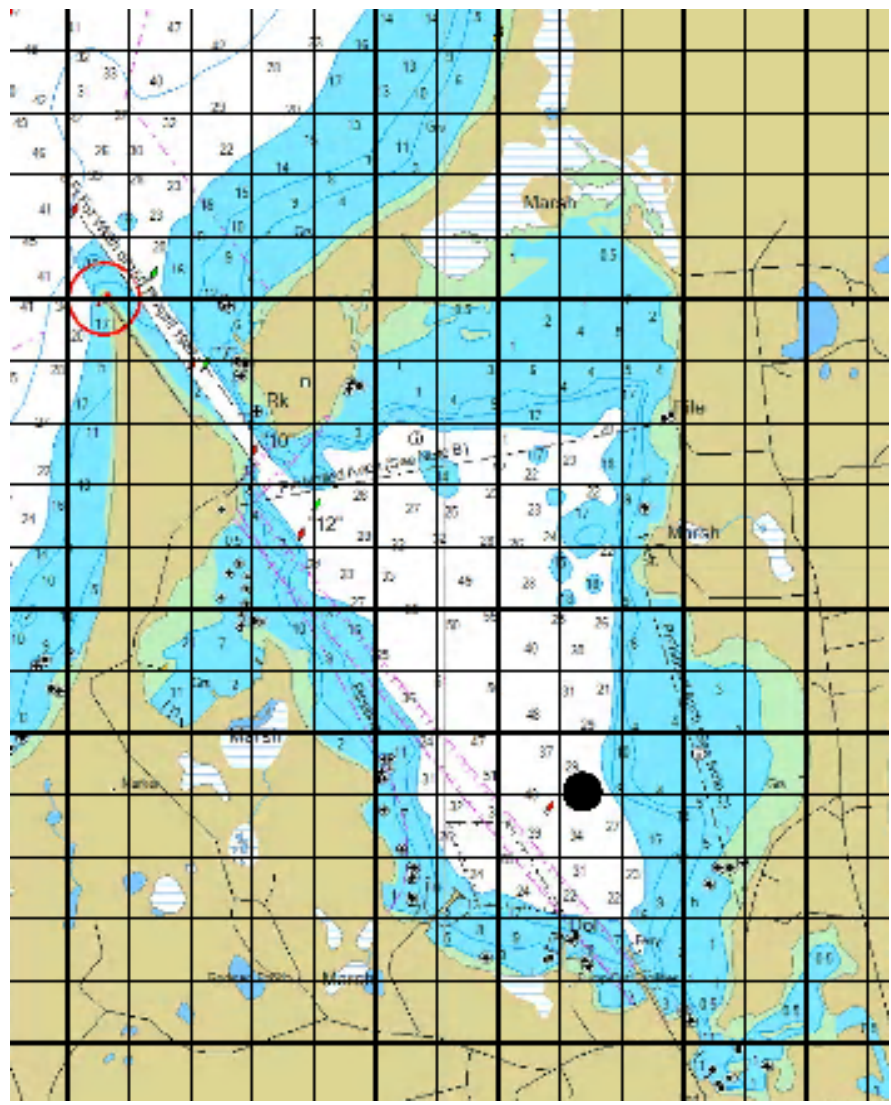

Figure 1: $\quad$ Bathymetry of Great Salt Pond, Block Island and the dye release position (O) used in the pollution flushing study [7]. The chart has been overlaid with a grid in order to acquire the depth data for the MSB pollution-flushing model. Reproduced from NOAA chart number US 13217.

Annual seasonal boat counts on Great Salt Pond have been rather constant since a precipitous drop in 1996. These data are shown in Figure 2.

For purposes of illustration in this study, the 2004 boat count data were used and these are shown in Figure 3.

The peaks noted in this data correspond to weekends and holidays during the recreational boating season.

\section{Extension of the MSB model to account for the pollutant loading associated with recreational boating}

The factor, $k$, in eqn. (1) represents the embayment pollution loading rate expressed in terms of a mass per unit time. The literature provides results of a 


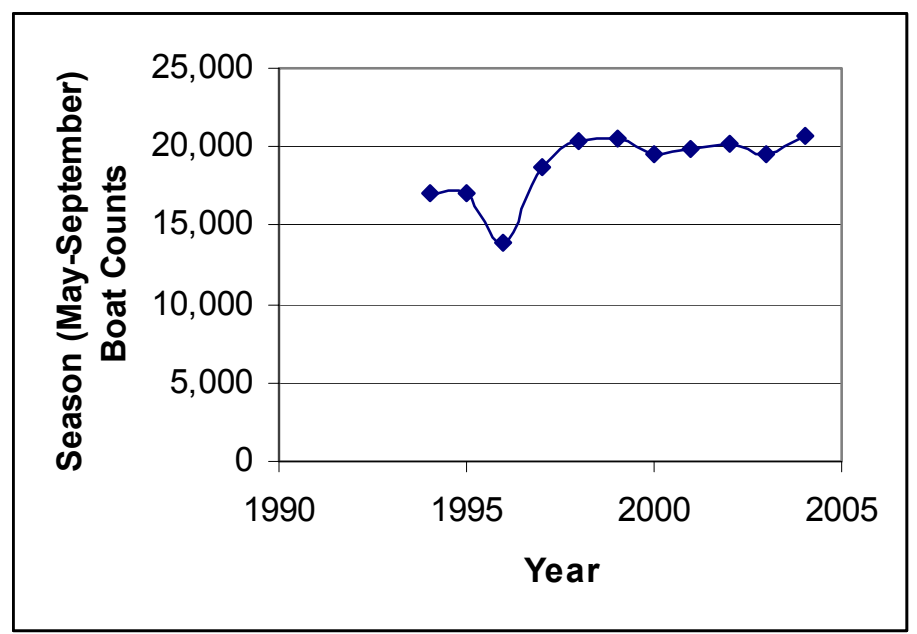

Figure 2: $\quad$ Annual seasonal boat counts for Great Salt Pond.

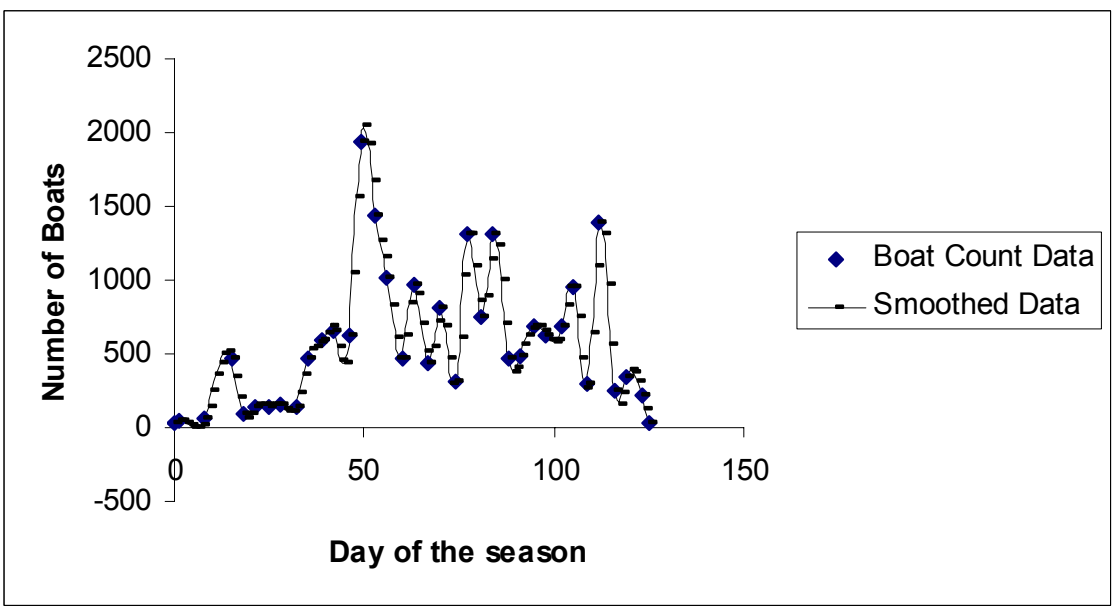

Figure 3: Seasonal boat count data for 2004 smoothed with a spline function.

number of studies on the pollutants associated with marine engine use [8-16]. Four of these studies $[8,9,10,16]$ were considered in the analyses reported herein. The pollution is often reported in grams of pollutant per horse-power hour with measurements being carried out for specific engine size and type and operating on specific vessel types and sizes. The array of boat types, hull shapes and engines will affect these pollutant values. A sample of the reported data used in the pollution loading section of the model is summarized in Table 1.

For a particular pollutant of mass, $m_{i}$, in $\mathrm{g} / \mathrm{hp}-\mathrm{h}$, the pollution loading factor for an engine type, $i$, can be defined as 
Table 1: $\quad$ Some common pollutant emissions associated with marine engine use computed using data from reference [8]. While other data for gasoline engines $[9,10]$ were considered, only that from [8] were used to obtain these results.

\begin{tabular}{lll}
\hline \multicolumn{3}{c}{ Emissions (g/hp-h) } \\
\hline Pollutant & 2-stroke & 4-stroke \\
\hline HC (g) & 240 & 12 \\
NMOG (g) & 256 & 12 \\
CO (g) & 488 & 142 \\
NO(x) (g) & 0.89 & 5.8 \\
PM (10 micrometers)* & 0.00604 & 0.00003 \\
PM (2.5 micrometers)* & 0.00604 & 0.00002 \\
1,3 butadiene (g) & 0.34 & 0.1 \\
benzene (g) & 2.98 & 0.4 \\
benzene (aq) & 0.16 & 0.052 \\
formaldehyde (g) & 0.21 & 0.045 \\
acetaldehyde (g) & 0.05 & 0.0075 \\
MTBE (aq) & 5.15 & 0.22 \\
toluene (aq) & 0.52 & 0.089 \\
ethylbenzene (aq) & 0.15 & 0.022 \\
\hline
\end{tabular}

Notes:

[8] Two 9.9 Hp outboards, a 2-stroke Evinrude and a 4-stroke Honda, were tested in a 757 litre test tank of water. Test cycle included five modes: mode $1=$ full speed, $2=.8$ speed, $3=.6$ speed, $4=.4$ speed, $5=$ idle. Each mode was run for ten minutes and a weighting factor was imposed to account for the varying amounts of fuel consumed by each mode. A weighted average emission rate for each pollutant was then determined from the emission rates at each mode and the weighting factor. Data analysis tools included infrared lasers, chemiluminescent analyzers, chromatography, and isokinetic sampling. Results in $\mathrm{g} / \mathrm{kW}-\mathrm{h}$ were converted to $\mathrm{g} / \mathrm{hp}-\mathrm{h}$.

*Tested with both a PM10 and a PM2.5 cyclone.

[9] Two Yamaha 4-stroke outboards (15 Hp and $8 \mathrm{Hp}$ ) were tested with gasoline and commercial butane. Test cycle included five modes: mode $1=$ full speed, $2=.8$ speed, $3=.6$ speed, 4=.4 speed, 5=idle. Each mode was run for the same amount of time and a weighting factor was imposed to account for the varying amounts of fuel consumed by each mode. A weighted average emission rate for each pollutant can be determined from the emission rates at each mode and the weighting factor. Gas analyzers used: Horiba Mexa 574GE NDIR, Horiba FIA-510 CLD, Horiba CLA-510SS FID. Results in g/kW-h were converted to $\mathrm{g} / \mathrm{hp}-\mathrm{h}$.

[10] One four-stroke Yamaha $9.9 \mathrm{Hp}(7.3 \mathrm{~kW})$ outboard engine was tested in an 800 litre tank of water. Average $\mathrm{rpm}=5600$. Runs averaged $10-15$ minutes on stand mounted to tank. Results given in $\mathrm{mg} / 10 \mathrm{~min}$ may be converted to $\mathrm{g} / \mathrm{hp}$-h based on estimates of average power output corresponding to the test engine size and rpm. Data analysis tools included gas chromatography and mass spectrometry. 


$$
k_{i}=f_{i} \cdot B C_{\text {total }}(t) \cdot m_{i} \cdot \sum_{B L R=1}^{4} g_{i, B L R} \cdot h p h b l(B L R) \cdot D
$$

where the subscript $i$ refers to the engine type with:

$1=$ inboard and auxiliary inboard

$2=2$-stroke outboards and auxiliary outboards

$3=4$-stroke outboards, auxiliary outboards and stern drive inboard-outboards

$4=$ personal water craft $(\mathrm{PWC})$ engines

the subscript $B L R$ refers to the boat length range with:

$1=0$ to $16 \mathrm{ft}$

$2=16$ to $26 \mathrm{ft}$

$3=26$ to $40 \mathrm{ft}$

$4=40+\mathrm{ft}$

$f_{i}=$ fraction of boats with engine type, $i$,

$B C_{\text {total }}(t)=$ total daily boat count at time, $t$ (days)

$g_{i, B L R}=$ fraction of type $i$ engine boats in the length range, $B L R$

$h \operatorname{phbl}(B L R)=$ average computed hp-hr energy required to move a boat of length range, $B L R$, a distance of 1 mile at the posted speed limit ( $5 \mathrm{mph})$, and $D=$ average distance travelled during a boat's stay in the embayment.

Eqn. (2) was computed using the array functions within Stella and a user interface was written to allow for convenient definition of input requirements and ready update of pollution values as the literature develops. The total pollution loading rate, $k$, is simply the sum of the individual values of $k$, i.e.

$$
k=\sum_{i=1}^{4} k_{i}
$$

The model structure and the interface are shown in Figures 4 and 5, respectively. Tracking individual vessels and determining the daily mix of vessel types in the basin is not practical and hence the model uses estimates of average distance travelled per vessel during a daily stay and profiles of boat registrations to set the distributions, $f$ and $g$, in eqn. (2).

\section{Application of the model}

In applying the model to Great Salt Pond, the value of the pollution return-flow factor, $b$, was set to 0.25 in accordance with the results from a previous study [6]. Bathymetric data and known tidal data for Great Salt Pond were used in the MSB model. Boat count data for 2004, as shown in Figure 3, were incorporated into the calculation of the pollution loading factor, $k$, from eqn. (2). While the boat count data did not differentiate on vessel type, size, and engine type and size, these distributions were obtained from registration and sales reports from the National Marine Manufacturers Association [17] and are summarized in Table 2 .

The model application assumes each vessel moves at a speed of $5 \mathrm{mph}$, the maximum allowable limit, and travels a total of 1 mile each day within the limits of the basin. This would correspond to an average distance from entrance to anchorage/mooring/dockage and back each day. 


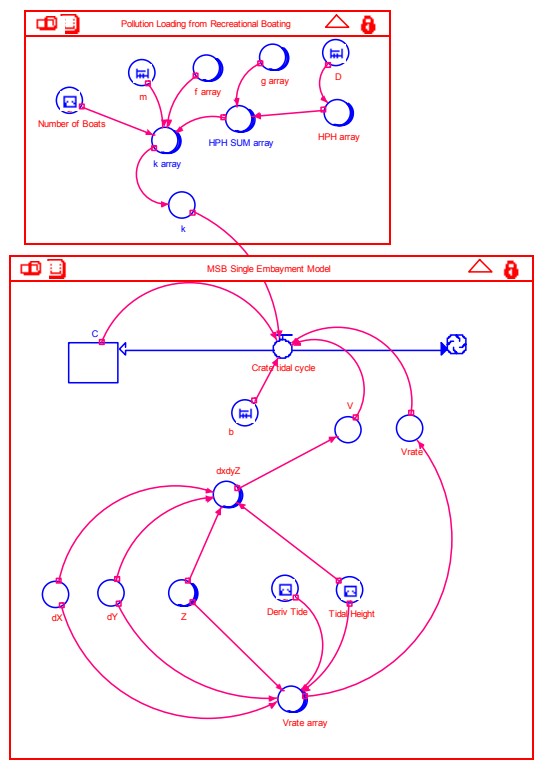

MSB Model Sector:

$\mathrm{C}(\mathrm{t})=$ Concentration of pollution

CrateFlood $=$ Rate of change in pollution concentration during flood tide.

CrateEbb $=$ Rate of change in pollution concentration during ebb tide.

$\mathrm{b}=$ Pollution return susceptibility parameter

Mean Water_Depth $=$ Average water depth at mean tide.

Period $=12.42$ hours in a tidal cy cle

Tidal_Height $=$ height above mean low tide $(\mathrm{m})$

Tidal_Range $=$ Total tidal swing from low tide and high tide $(\mathrm{m})$

$V=$ Volume of the embay ment $(\mathrm{m} 3)$

Vrate $=$ Change in volume $\mathrm{V}$ over time based on tides

$\mathrm{dX}=$ Length of grid block

$d x d y Z[i, j]=$ Volume of every block in the embayment grid at time (t)

$\mathrm{dY}=$ Width of grid block

max Tide $=$ Max tidal swing $(\mathrm{m})$

Deriv Tide $=$ Deriv ative of Tidal Height

$Z[i, j]=$ Bathy metric data array for embay men

Pollution LoadingSector:

$D=$ Average distance (miles) from mouth of harbor to mooring and back.

$f=$ Fraction of all boats that are a specific engine type.

$g=$ Fraction of all boats that are a specific engine type in a specific size

range.

$\mathrm{HPH}=$ Energy required (hp-h) to propel boat $\mathrm{D}$ miles.

HPH SUM = Total energy required to propel all boats of a certain engine ty pe

$k=$ Pollution loading rate (mass per unit time)

$\mathrm{k}$ array $=$ An array of pollution contributions from each engine ty pe.

$\mathrm{m}=$ Mass of pollutant $(\mathrm{g})$ emitted during $1 \mathrm{hp}-\mathrm{h}$ of engine operation.

Number of Boats $=$ Number of boats in harbor per hour of the year.

Figure 4: Model structure showing both the MSB and pollution loading segments.

\begin{tabular}{||l|l|l|}
\hline \multicolumn{1}{|l|}{ IU } & \multicolumn{2}{c|}{ Input Paramters } \\
\cline { 2 - 3 } & b & 0.25 \\
\hline & m & 0.09 \\
\hline & D & 3 \\
\hline & & \\
\hline & & \\
\hline
\end{tabular}

Input and Output Parameters Defined:

$b=$ Pollution return flow factor. Varies from 0 , for no return flow, and 1 , for

total return flow

$\mathrm{m}=$ Grams of pollutant emitted during $1 \mathrm{hp}-\mathrm{h}$ of engine operation

$\mathrm{D}=$ Average distance from mouth of harbor to mooring and back

$\mathrm{C}=$ Pollution concentration

$\mathrm{K}=$ Pollution loading rate (mass per unit time)

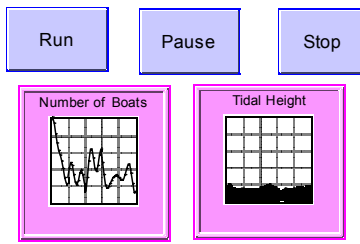

\begin{tabular}{|l|c|c|}
\hline & Emissions (g/hp-h) [8] \\
\hline Pollutant & 2-stroke & 4-stroke \\
\hline benzene (aq) & 0.16 & 0.05 \\
\hline MTBE (aq) & 5.15 & 0.22 \\
\hline toluene (aq) & 0.52 & 0.09 \\
\hline ethylbenzene (aq) & 0.15 & 0.02 \\
\hline xylenes (aq) & 0.41 & 0.07 \\
\hline
\end{tabular}

[8] Gabele, Peter A., Pyle, Steven M., Emissions from Two Outboard Engines Operating on Reformulated Gasoline Containing MTBE, Environmental Science and Technology, 2000, 34, 368-372.
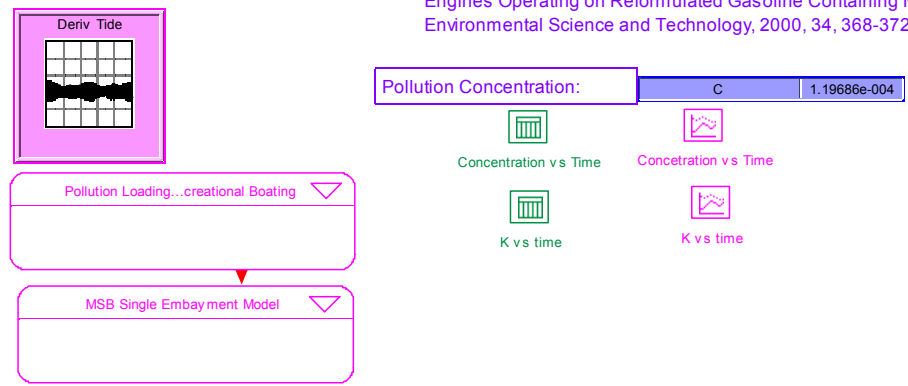

Figure 5: User interface for the model. 
Table 2: Assumed distribution of boat power types by boat length range [17]. (Total percentage of all boats is a little higher than $100 \%$ due to round-off errors.)

\begin{tabular}{lccccc}
\hline LOA (ft) & $\begin{array}{c}\text { Percent } \\
\text { of all } \\
\text { boats }\end{array}$ & $\begin{array}{c}\text { Inboard/ } \\
\text { Auxiliary } \\
\text { Inboard }\end{array}$ & $\begin{array}{c}\text { Outboard/ } \\
\text { Auxiliary } \\
\text { Outboard }\end{array}$ & Sterndrive & PWC \\
\hline $\mathbf{0 - 1 6}$ & $43.73 \%$ & $4.00 \%$ & $31.81 \%$ & $1.32 \%$ & $6.60 \%$ \\
$\mathbf{1 6 - 2 6}$ & $51.95 \%$ & $6.40 \%$ & $34.11 \%$ & $11.44 \%$ & $0 \%$ \\
$\mathbf{2 6 - 4 0}$ & $4.00 \%$ & $1.80 \%$ & $0.96 \%$ & $1.24 \%$ & $0 \%$ \\
$\mathbf{4 0 +}$ & $0.60 \%$ & $0.41 \%$ & $0.08 \%$ & $0.11 \%$ & $0 \%$ \\
\hline
\end{tabular}
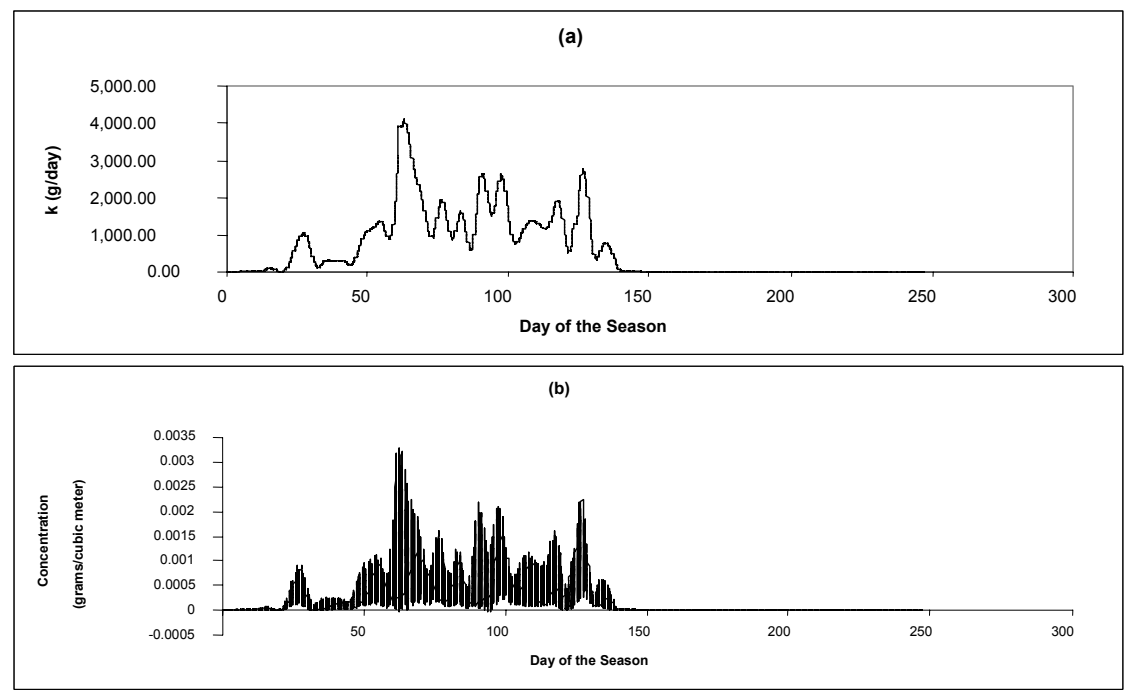

Figure 6: (a) Pollution loading rate, $k$, for ethylbenzene release; (b) concentration results from the MSB pollution-flushing model.

\section{Results}

A particular pollutant, ethylbenzene, was chosen in the present study. The pollution loading rate was calculated from eqns. (2) and (3) with $m_{i}$ determined by weighting aqueous ethylbenzene emissions for the various engine types using a distribution reflecting that $96 \%$ of all engines are gasoline of which $45 \%$ are 4 stroke. Figure 6a represents the aggregate pollution loading rate as a function of the day of the boating season, with day 1 being defined as May 1. The concentration in $\mathrm{g} / \mathrm{m}^{3}$ was simulated for the boating season using the MSB model driven by the pollution loading function and the results are shown in Figure $6 \mathrm{~b}$. Not surprisingly, the pollution concentration appears to follow the pollution loading rate in these results. 
The obvious periodicities prompted a Fourier analysis of the time series. Indeed the results, shown in Table 3, clearly align with the principal harmonic components of the tidal spectrum [18]. The $C / k$ spectrum exhibits other peaks corresponding to excursions in the time series that are the result of the flushing conditions of the embayment environment including the return flow and the pattern of pollution loading. Such spikes represent a short-term pulse in pollution concentration above what would normally be expected from the pattern of pollution loading based on boating activity at the time of the pulse.

Table 3: Components of the $C / k$ spectrum of Figure 7 compared to the harmonic components of the tidal spectrum.

\begin{tabular}{|c|c|c|c|c|}
\hline \multicolumn{3}{|c|}{ Tidal components - periods and frequency } & \multicolumn{2}{|c|}{$C / k$ frequency } \\
\hline Component & T(hrs) & T(days) & f(1/days) & f(1/days) \\
\hline principal lunar semidurnal & 12.42 & 0.5175 & 1.932367 & 1.93 \\
\hline principal solar semidurnal & 12.00 & 0.5000 & 2.000000 & 1.97 \\
\hline elliptical lunar semidurnal & 12.66 & 0.5275 & 1.895735 & 1.90 \\
\hline $\begin{array}{c}\text { semidiurnal } \\
\text { declinational luni-solar }\end{array}$ & 11.97 & 0.49875 & 2.005013 & 2.00 \\
\hline diurnal & 23.93 & 0.997083 & 1.002925 & 1.00 \\
\hline principal lunar diurnal & 25.82 & 1.075833 & 0.929512 & 0.93 \\
\hline
\end{tabular}

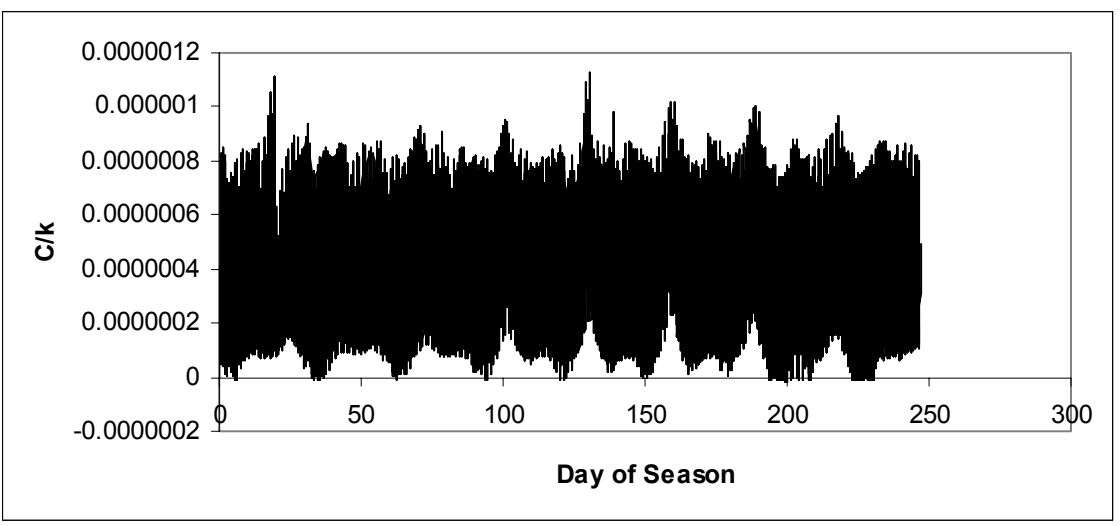

Figure 7: The ratio of the pollution concentration to the pollution loading rate in Great Salt Pond.

\section{Conclusions}

The MSB model has been used to estimate the flushing of pollution in a wellmixed tidal basin that is subjected to recreational boating activities. Key pollutants associated with recreational boating have been ascertained from studies reported in the literature. A sample analysis has been carried out for a 
particular pollutant, ethylbenzene, resulting from recreational boating activities in Great Salt Pond (Block Island) for the 2004 boating season. The model is flexible enough to allow the analysis of a wide range of aqueous pollutants.

\section{Acknowledgements}

Padhraic Mulligan is gratefully acknowledged for his efforts supporting this study while he was a student in the Systems Dynamics Research Group in the Department of Engineering-Physics-Systems at Providence College. We would also like to thank Chris Willy, Harbormaster on Block Island, who graciously provided the boat count data for Great Salt Pond.

\section{References}

[1] Mecca, S.J., Severino, C. \& Barber, R.W., Pollution flushing models in Stella, Development and Application of Computer Techniques to Environmental Studies $X$, edited by G. Latini, G. Passerini and C.A. Brebbia, pp. 125-134, WIT Press: Southampton, UK, 2004.

[2] Mecca, S.J., Severino, C. \& Barber, R.W., Pollution flushing in cascading tidal basins, WIT Transactions on The Built Environment, 78, pp. 93-100, edited by M. da Conçeicao Cunha and C.A. Brebbia, WIT Press: Southampton, UK, 2005.

[3] Mecca, S.J., Barber, R.W. \& Tombarello, J., Alternative loading functions in the MSB pollution flushing model, WIT Transactions on Ecology and the Environment, 88, pp. 89-97, edited by C.A. Brebbia, WIT Press: Southampton, UK, 2006.

[4] Barber, R.W., Analytical modeling of pollution flushing in well-mixed tidal embayments, Chapter 17, Advances in Coastal Modeling, edited by V.C. Lakhan, Elsevier Science B.V., 2003.

[5] Sanford, L. P., Boicourt, W. C. \& Rives, S. R., Model for estimating tidal flushing of small embayments, J. Waterway, Port, Coastal and Ocean Eng., 118 (6), pp. 635-654, 1992.

[6] Mecca, S. J., Barber, R. W., Mellor, G. \& Walsh, G., Application of the MSB pollution-flushing model to Great Salt Pond on Block Island, WIT Transactions on Ecology and the Environment, 104, pp. 189-197, edited by C. A. Brebbia and K. L. Katsifarakis, WIT Press: Southampton, UK, 2007.

[7] Hydrographic Study of Great Salt Pond, Block Island, Rhode Island, October 2-6, 1986. New England Technical Services Unit, Davisville, Rhode Island, September 1987, Department of Health and Human Services, Public Health Service, Food and Drug Administration, Shellfish Sanitation Branch, (Unpublished).

[8] Gabele, P. A. \& Pyle, S. M., Emissions from two outboard engines operating on reformulated gasoline containing MTBE, Environ. Sci. Technol., 34, pp. 368-372, 2000.

[9] Murillo, S., Viability of LPG use in low-power outboard engines for reduction in consumption and pollutant emissions, Int. J. Energy Research, 27, pp. 467-480, 2003. 
[10] Juttner, F., Emission of aromatic hydrocarbons and aldehydes into the water by a four-stroke outboard motor; quantitative measurements, Chemosphere, 29, pp. 191-200, 1994.

[11] Wachsa, B., Two-stroke engine lubricant emissions in a body of water subjected to intensive outboard motor operation, The Science of the Total Environment, 116, pp. 59-81, 1992.

[12] Yousef, A., Assessing effects on water quality by boating activity, Environmental protection technology series, EPA-670/2-74-072 National Environmental Research Center, Cincinnati, 1974.

[13] Juttner, F., Motor-boat-derived volatile organic compounds (VOC) in lakewater, J. Water and Waste Water Research, 21, pp. 36-39, 1988.

[14] Arapatsako, C.I., Air and water influence of two stroke outboard engine using gasoline-ethanol mixtures, SAE Technical Paper Series, 2000-02973.

[15] Wasil, J.R., Life assessment of PM, gaseous emissions, and oil usage in modern marine outboard engines, SAE International 2004 - 320092/20044379.

[16] Tang, S., Frank, B. P., Lanni, T., Rideout, G., Meyer, N., and Beregszaszy, C. Unregulated emissions from a heavy-duty diesel engine with various fuels and emission control systems, Environ. Sci. Technol., 41, 14, 5037 5043, 2007.

[17] National Marine Manufacturers Association, 2005 U.S. Recreational Boat Registration Statistics, Industry Statistics and Research Department.

[18] Gjevik, B., Lectures on tides, UNIS, Longyearbyen, 18-22 Oct. 2004, Department of Mathematics, University of Oslo, Oslo, Norway. 